\title{
Reflecting on BEd students' experiences of unfamiliar school contexts during school-based learning: A proposition for transformative learning
}

\section{Deidre Geduld}

Head of Department: Primary School Education - Foundation Phase, Faculty of Education, Nelson Mandela University, Port Elizabeth, South Africa

Deidre.Geduld@mandela.ac.za

https://orcid.org/0000-0001-6175-0508

\section{Heloise Sathorar}

Head of Department: Secondary School Education - Senior Phase, Further Education and Training Phase and Post Graduate Certificate in Education, Faculty of Education, Nelson Mandela University, Port Elizabeth, South Africa

Heloise.Sathorar@mandela.ac.za

https://orcid.org/0000-0002-4947-0885

\section{Muki Moeng}

Executive Dean, Faculty of Education, Nelson Mandela University, Port Elizabeth, South Africa Muki.Moeng@mandela.ac.za

https://orcid.org/0000-0001-9805-766x

(Received: 13 February 2020; accepted: 16 September 2020)

\section{Abstract}

As critical teacher educators, we advocate the transformational potential of school-based learning (SBL). Changing practice teaching contexts to accommodate unfamiliar SBL environments for student teachers offers them an excellent opportunity to develop critical skills as transformative intellectuals and agents of change. Yet anxiety about unfamiliar placements often prevents them from making the most of potential learning experiences. In this paper, we generated data via World Café conversations in which final-year Bachelor of Education (BEd) student teachers described their experiences of operating in an unfamiliar schooling context. The findings suggest that changing the SBL context can enable transformative learning experiences using critical pedagogy principles. Student teachers reported that they not only developed classroom skills, knowledge, confidence, and a deeper appreciation of learning opportunities through changing practice teaching contexts, but that they also gained a new understanding of what teacher transformative learning involves.

Keywords: school-based learning, critical pedagogy, transformative learning 


\section{Introduction}

Preparing student teachers for alternative contexts within and between schools is a growing focus in teacher education not only in South Africa, but worldwide. Exposing student teachers to alternative contexts during school-based learning (SBL) still poses serious challenges to teacher education (Botha \& Baxen, 2018). South Africa is faced with many contradictions that continue to plague us more than two decades after our first democratic elections. These contradictions continue to prevail in the schooling system with an everwidening gap that divides rich and poor, black and white, privileged and underprivileged in our schools whose purpose it is to serve society. Teacher education should focus on preparing student teachers to "challenge creatively . . . concepts of diversity which transcend respect for difference and confront power and inequality" (Botha \& Baxen, 2018, p. 448). Student teachers need to be prepared to be agents of change and transformative intellectuals (Sathorar $\&$ Geduld, 2019). They need to close the ever-present gap between policy ideals of equality and the reality on the ground. We argue that student teachers must be prepared to teach in the range of different schools in South Africa (SA), some of which operate without textbooks, computers, internet, and basic items such as electricity, water, and sufficient desks. Schools in SA require resilient teachers who are courageous enough to risk, explore, experiment, learn, and change the challenging conditions experienced by many schools (Geduld \& Sathorar, 2016).

This paper was inspired by a broader faculty of education re-curriculation process through which SBL was reconceptualised to consider the contexts in which students are placed for their teaching practice. The faculty decided to place students in more diverse school contexts, including those most unfamiliar in terms of their own schooling, in order to encourage them to become agents of change and have a better understanding of transformative learning. This was a purposeful, deliberate, and considered approach to expose students to epistemological dilemmas that would help them create links between theory and practice while developing political consciousness that sensitised them to issues of equity, justice, and social inclusion (Favish et al., 2012). Historically, students have tended to choose practice teaching placements in contexts similar those in which they themselves were schooled. Against this background, this paper offers an illustrative case of how SBL can offer transformative learning opportunities via different school and classroom contexts.

\section{Problem statement}

SBL constitutes a major component of the teacher education curriculum. Through this exposure, student teachers encounter authentic teaching and learning experiences upon which they are expected to critically reflect (Lam et al., 2007). SBL provides an opportunity for student teachers to relate their theoretical knowledge to real classroom practice (Shumba et al., 2016). According to the Minimum Requirements for Teacher Education Qualifications (MRTEQ), student teachers are expected to learn from, learn about, and learn in practice (Department of Higher Education and Training [DHET], 2015). Furthermore, such encounters provide fertile ground for the interplay between different types of knowledge and 
practices that can enable student teachers to work flexibly and effectively in a variety of contexts (DHET, 2015).

Despite the introduction of transformative school policies and various attempts to improve the South African schooling system, structural and systemic inequalities persist in South African schools. According to the Schools Act of 1996, the new schooling system's intention was to try to eradicate the inequalities of the past by redressing past injustices and by encouraging democratic citizenship (Department of Education, 1996). Even though more and more South African classrooms reflect the diversity of the South African community, most township schools and some ex-Model C schools still reflect the structural and cultural conditions of the past (Spaull, 2019). This reality can be a huge hurdle for student teachers to cross when they have to choose schools for their SBL placements.

The inequality and disparity in the schooling system encourages student teachers to choose to go to schools that they know, and where they feel comfortable. They select well-resourced schools or schooling contexts that are known to them, and where they believe that they will be supported. They make this selection based on inherent assumptions and unfounded beliefs about alternative school contexts (Ravitch, 2020). This creates a vicious cycle of wellresourced schools being advantaged at the cost of under-resourced schools, and further perpetuates the inequalities in the system. In this crisis of ever-increasing inequality in the schooling system, student teachers must be prepared to be courageous and to risk, explore, and experiment to bring about social change. Exposing student teachers to different schooling contexts will encourage the development of an inquiry-based mindset that is adaptive, generative, and compassionate.

\section{Theoretical orientation}

Critical pedagogy is informed by critical theory (Freire, 1970, 1996; Giroux, 1988; McLaren, 2003). Both critical theory and critical pedagogy are concerned with countering oppressive powers and resisting dominant cultures and institutions (Nouri \& Sajjadi, 2014). However, critical pedagogy focuses specifically on education and seeks to provide a response to the oppressive power relations and inequalities existing in many educational institutions (Keesing-Styles, 2003). According to Biesta (1998), the liberatory interest of critical pedagogy encourages a critical analysis of educational practices and theories in order to highlight how they often perpetuate inequalities. Critical pedagogy can, through critical reflexivity, provide opportunity to gain a better understanding of one's lived experiences. Exposing student teachers to different schooling contexts creates an opportunity to analyse the oppressive powers in teacher education, particularly regarding teaching practices that contribute to the inequalities that exist and continue to increase in the schooling system. It also creates an opportunity for student teachers to examine their own inherent assumptions through a critical lens that helps them to engage, understand, and relate to the alternative context. 
Shor (1992) described critical pedagogy as a student-centred programme that promotes multicultural democracy in schools and society and that views individual growth as the result of active cooperation between the self and society. Thus, critical pedagogy links personal growth to public life by developing strong skills of inquiry that are supported by academic knowledge concerned with societal power relations and inequalities. Teacher educators thus, need to facilitate a process through which students can identify oppressive actions and then encourage them to question dominating ideologies in order to engage them in liberatory activities on a personal as well as a collective level (Riasati \& Mollaei, 2012). Encouraging student teachers to do their SBL in an unfamiliar context allows them to problematise dominant educational and social arrangements, and contributes to the development of multicultural democracy in schools and society at large.

Critical pedagogy covers a broad spectrum of issues but for this paper, we focus on teachers being transformative intellectuals and contributing to social transformation. As pointed out by McLaren (1998), critical pedagogues agree that their aim is to provide liberation for the powerless and to pursue transformation by eradicating inequalities and injustices. Thus, according to Foley, the goal of critical pedagogy is

not only to expose both the forces of, and the tactics used by dominant groups aiming to marginalize others, but also to develop the ability in less powerful groups to create a counter discourse that may lead to the transformation of master narratives into narratives that are multicultural and multi-vocal. $(2007$, p. 6)

Similarly, Aliakbari and Faraji (2011) postulated that the major goals of critical pedagogy reside in critical consciousness raising and the rejection of all oppressive actions against people. They further posited that critical pedagogy aims to support oppressed people and to free them from being mere objects of education so they can become subjects of their own learning and liberation. Fitzpatrick corroborated that view; for him, the purpose of critical pedagogy was to engage learners in the act of "what Freire calls conscientization," which can be defined as "learning to perceive social, political and economic contradictions, and to take action against the oppressive elements of reality" (2013, p. 124). Furthermore, Nagda et al. (2003) postulated that educational efforts informed by a critical approach acknowledge that the challenge in educating for transformation involves more than the instilling of knowledge; it requires accompanying action. It thus "requires an on-going process of changing the environmental, cognitive and pedagogical contexts in which teaching and learning occur" (Nagda et al., 2003, p. 167). In this paper, we propose action in line with key notions of critical pedagogy by disrupting views of the dominant discourse; student teachers are now required to do part of their SBL in a context not known to them in order to expand their frame of reference beyond the technical aspects of lesson plans.

\section{A case for transformative learning}

According to Soudien (2010), there are basically two main approaches to the question: "What is transformation?" The first approach sees transformation as a demographic intervention 
around the imbalances of race, class, gender, and language; the second argues that it is about the nature of privilege and power. The first approach focuses on representation, and the second approach argues that transformation is an ideological process that has to engage with domination and its attendant forces and discourses. Both these approaches resonate with the authors, but the second approach informs the writing of this paper. Thus, transformation in this paper refers to the distribution of political and economic power in society and the processes through which social inclusion and exclusion are affected. In order to bring about transformation, a process of transformative learning is proposed.

Mezirow's (1991) transformative learning theory is linked to critical pedagogy through its aim of bringing about change. He claimed that the theory explains how students make sense of their experience by revealing how social and other structures influence the way they construe that experience; and by showing how the dynamics involved in modifying meaning can undergo change when students find them to be dysfunctional (Mezirow, 1991). Thus, transformative learning is a process that has as its aim, the changing of one's frame of reference and, as such, it can bring about changes in perceptions and assumptions (Kress, 2011; Mezirow, 1997). Christie et al. (2015) concurred that the aim of transformative learning is to help individuals challenge the current assumptions on which they act and, if these are found wanting, to change them. This would involve both a mental and a behavioural shift.

In his transformative learning theory, Mezirow (1991) argued that every individual has a particular view of the world. This view may or may not be well-articulated but is usually based on a set of paradigmatic assumptions that are derived from the individual's upbringing, life experience, culture, and education. He further claimed that individuals have difficulty in changing worldviews that have become unconscious frames of reference created by habits of the mind. These points of view can become so ingrained that it takes a powerful human catalyst, a forceful argument, or what he called a disorienting dilemma to shake them (Mezirow, 1991, 1997). Furthermore, it appears that transformative learning is underpinned by conscientisation (Christie et al., 2015; Kitchenham, 2008) derived from critical reflections of current reality. Therefore, transformative learning involves critically reflecting on one's perceptions and assumptions with the aim of rethinking reality in order to establish change within the self or, as Dirkx (1998, p. 2) put it, by ensuring "consciousness raising." Thus, it seems that the aim of transformative learning is to promote and influence personal change by reviewing and questioning current beliefs and worldviews (Kerr, 2014).

Kitchenham (2008) and Christie et al. (2015) reflected on Mezirow's (1991, 1997) ten steps that can serve as a guide to enhance the transformative learning process. These steps do not have to be completed in a linear manner, nor do all the steps have to be completed. The steps are as follows: disorienting dilemma, self-examination, sense of alienation, relating discontent to others, explaining options of new behaviour, building confidence in new ways, planning a course of action, knowledge to implement plans, experimenting with new roles, and reintegration. Four of Kitchenham's variations of the steps that were of particular relevance to our changing SBL context process were: "being confronted with a disorienting 
dilemma," "embarking on a process of self-examination (that could be accompanied) with feelings of guilt or shame," "a critical assessment of epistemic, socio-cultural or psychic assumptions," and "the recognition that your discontent and the process of transformation are shared and that others have negotiated a similar change" (2008, p. 105).

We presented our students with a disorienting dilemma when we required them to change schools midway during their SBL in their final year. They were required to go to an unfamiliar school context. This caused resistance and several students baulked at the requirement. Hence, we had to assist students - through discussion and questioning - to embark on self-examination in order to discover why they were not willing to change SBL contexts. Students had to identify and acknowledge the epistemic, sociocultural, and psychic assumptions they had about the unknown contexts. We highlighted the fact that they were not alone in this process by getting students to share their realities about their familiar contexts with their peers.

To harvest the benefits of transformative learning, we engaged our students in a process of reflection and dialogue. This process assisted students in exploring the depth and breadth of their perceptions and assumptions relating to the changes in school context they had experienced. Moreover, they reflected on what was required of them in order to make the change in context a transformative learning experience. Through this dialogue, students were allowed to articulate their thoughts about the situations they experienced, and were able to reflect on their concerns after they heard from peers who came from those different contexts. This allowed them to reconsider their previous assumptions and so achieve greater clarity for themselves (Christie et al., 2015; Mezirow, 1997).

The process of changing SBL contexts and engaging in a transformative learning process allowed student teachers to gain insight into alternative schooling contexts as well as into what is expected of a transformative intellectual. Giroux (1983), Habermas (1981), and Freire (1970) defined teachers as transformative intellectuals by emphasising the role they play in the mediation of teaching and learning. Freire (1970) further highlighted the importance of teachers in bringing about social change; they should make the pedagogical more political and the political more pedagogical. Teacher educators need to expose the reproductive role of education and to instil faith in student teachers to overcome the economic, social, and political struggle and to educate and humanise themselves as part of that struggle (Fien, 1993). It is thus imperative that teacher educators create opportunities for student teachers to participate in the learning process by making knowledge problematic, and making the struggle for a better world a conscious educational goal (Fien, 1993). This confirms the reason we required student teachers to teach in unfamiliar contexts.

\section{Research methodology}

This qualitative study examines the experiences of BEd fourth-year student teachers in an unfamiliar school context by referring to critical pedagogy principles through their implementation in Mezirow's (1991) transformative learning steps as research framework. In 
particular, the four transformative learning steps described by Kitchenham (2008) as discussed above were used as a critical lens through which the student teachers' experiences were explored.

The faculty of education programmes are offered across two campuses, namely, Missionvale Campus and South Campus. As part of a faculty-wide research-based project on SBL, data was collected from all BEd undergraduate fourth-year students through reflective meetings in their respective educational phases. A total of 315 students were invited to these sessions. In this paper, we focus on the data gathered from the BEd foundation phase (FP) and BEd, further education and training (FET) students because the placement of students from these phases was more diverse with regard to context. The diverse placements in these phases are informed by the mother tongue education requirement in FP and the subject-specific specialisations in the FET phase. The BEd intermediate phase did not form part of the research study. Fifty-five of the 70 invited FP students, and 43 of the 80 invited FET students attended the respective sessions. Attendance was voluntary. Thus, the data that informed this paper was collected during the FP and FET meetings, and the participants were the $55 \mathrm{FP}$ and 43 FET students who attended the respective meetings.

The World Café (http://www.theworldcafe.com/) conversation technique was used to elicit student input regarding their experiences of changing schooling contexts for SBL. This allowed opportunities for all the participants to contribute to the pertinent issues under discussion in smaller groups that would subsequently report back to the bigger group. According to Brown and Isaacs (2007), the World Café conversation strategy is a simple but powerful conversation process that promotes constructive dialogue in groups of all sizes. It allows for conversations to be linked and to build on each other as participants move between groups. Moreover, it encourages the cross-pollination of ideas and creates opportunities for participants to discover new insights. Furthermore, the World Café conversation technique promotes an understanding of participants' perspectives and can even prompt the reexamination of one's own beliefs, thereby providing deep learning opportunities for participants (Brown \& David, 2005).

According to Brown and Isaacs (2007), the World Café strategy takes place in the following way: There should be the same number of tables as the number of questions that you would like to discuss. A host should be identified to facilitate and record the discussion at each of the tables. The host will remain at the table when fellow participants move to a different table; this host will then welcome new groups and share the ideas that were contributed by the members of the previous group. Participants can join any table discussion to start off with, and will move to different tables after a set time has elapsed. A facilitator will manage the movements between discussion tables and ensure that participants visit all the tables during the process. After the rotation process to the different tables has been completed, the hosts from each table will provide a synopsis of the ideas shared at their table to the whole group. The facilitator allows time for clarification questions and additional input after every host has presented their synopsis. 
We had five discussion questions that assisted us in gathering data to respond to the main research question: "How can exposing student teachers to alternative schooling contexts during SBL contribute to transformative learning?" The five discussion questions were as follows:

1. Why did you initially resist the change in schooling contexts for SBL, or why do you think your peers resisted the change in schooling contexts?

2. What made you (students) anxious about changing schooling contexts?

3. What were your perceptions of the alternative schooling contexts where you were placed?

4. What was your best learning experience while doing SBL in the alternative context?

5. How can we use your learning experience during the changing of schooling context to strengthen our SBL module?

The data collected during the respective meetings was recorded on newsprint and subsequently typed up. The researchers facilitated the process during the meetings.

This research study forms part of a larger faculty wide project regarding SBL. Ethical approval for the overarching project was attained from the relevant authority at the university where the study was conducted. Ethical guidelines as prescribed by the ethics committee were followed. The data was managed using ethical principles. The authors are co-owners of the data. A digital repository where the data was saved was created and the authors were able to access the data with a password.

As stated earlier in this research paper, the fact that the study only focused on data collected from two of the three undergraduate BEd groups (for reasons stated above) at one university suggests that its findings may not be generalised to other similar contexts. Although the findings may not be generalised, they may contribute towards a better understanding of student teacher experiences in alternative SBL contexts.

\section{Presentation and discussion of data}

The analysis of the data set demonstrates that all is not lost in the South African basic education system. An analysis of the data that was gathered suggests that the fostering of transformative learning as a principle of critical pedagogy in teacher education is feasible. SBL experiences as prescribed by the MRTEQ (DHET, 2015) can play a purposeful role in facilitating transformative learning (Sathorar \& Geduld, 2018). According to Mountford (2005), the education of student teachers stretches far beyond knowledge and skills acquisition, for example, the extent of their biases and assumptions must be recognised and, if necessary, challenged during their teacher preparation programmes. This view was shared by Posner et al. (cited in Boling, 2007), who argued that it is the responsibility of faculties of education to introduce new concepts and ideas in ways that create cognitive dissonance and, where necessary, transform the images, assumptions, and beliefs that their students hold. Below, is an exposition of the data collected with reference to Kitchenham's (2008) transformative learning steps. 


\section{Step 1: Disorienting dilemma}

Students should have a disorienting experience or unsettled situation. It will allow them to critically reappraise or evaluate their ways of knowing, thinking, and understanding. Several student teachers in the the BEd FP and FET programmes did not welcome the idea of a change in contexts for SBL during 2018. The innovative project was met with many challenges including a lack of student preparation, institutional constraints, and students and schools who resisted the suggested change. Some student teachers felt that the mooted change in school context required them to move from the known to the unknown, and that moving into uncharted territory would deprive them of familiar references to draw on. Many students angrily voiced objections about the changing schooling context, for example, one student said:

I'm not going to the Northern Areas. These areas are known for gangsterism, high crime rates and drug trafficking.

On the other hand, black students highlighted different objections, for example,

I am not going to a school consisting of a white-only staff, and where the only black people at the school are either general workers or cleaners. The staff and learners will be prejudiced against me.

Thus, many student teachers, when confronted with the disorienting dilemma of having to change their schooling context for SBL purposes, refused to engage with the process. They mentioned fears of not being allowed to teach in the alternative context schools they were being placed in. One FET student highlighted:

I am afraid that the teachers will not trust my ability ... most of the times the teachers mention that they do not have time to waste because they have curriculum outcomes to meet and time is money. Teachers that don't know me will not allow me to teach under these circumstances.

In response to students' rejection of going to an alternative SBL context, the faculty unpacked suggestions as proposed by Ladson-Billings (2006) regarding how to equip and prepare to work in an unfamiliar context, namely, the first thing student teachers should do is educate themselves about both the local socioeconomic and political issues of their school community (e.g., school governing board policy, community events) and the larger socioeconomic and political issues (e.g., unemployment, health care, housing, cultural responsiveness, learner diversity) that impinged on their learners' lives. We supported this by inviting student teachers from different contexts to share their experiences of living and being schooled in those contexts. Student teachers who were placed in schools in these contexts were allowed to ask clarifying questions. Student teachers were also encouraged to visit alternative school contexts to familiarise themselves with them before starting their SBL.

Mezirow (2000) proposed that for student teachers journeying on this road of transformative learning, opportunities to analyse their subjective experiences should challenge previously 
perceived notions of relationships and interactions between their own agency (personal power) and external structures (externally imposed environments and influences). Changing schooling context experiences afforded our student teachers the opportunity to become more aware and critical of the role of the broader community around them and of the systemic challenges facing schools.

\section{Step 2: Self-Examination}

The purpose of critical pedagogy is to enrich students' overall lives. In such an approach, students are given the chance to challenge their own and others' accepted assumptions and to explore the relationship between their society and the content of their educational environment. Critical pedagogy aims to help students be empowered, and to make them capable of achieving self-awareness and self-actualisation in order to transform their inappropriate conditions into something better (Freire, 1984). Being critical requires one to take action and to reflect on symbiotic relations in order to move nearer to authentic praxis (Freire, 1996).

The complexity of life and work cannot be summed up in the modules presented at university; student teachers need critical inquiry skills and real-life experiences. Freire (2007) mentioned that his life experiences motivated him and that ignorance, illiteracy, and the silence culture are the outcomes of economic conditions and of social and political trends prevalent in society. From his perspective, the educational system is one of the main instruments of maintaining a culture of silence: One FP student elaborated as follows:

I wasn't prepared for the complexity of teaching. I was convinced that my childhood dream to become a foundation phase teacher would bring me closer to live my fairytale. I was not open to dialogue where I felt my assumptions were being challenged. I chose to remain silent and not communicate. I became so much aware of existing social injustices in the school community I found myself, through collaboration with my school community.

Student teachers' capacity as teachers to observe, learn, reflect, and create new practices in changing contexts were improved as they were better able to contextualise because they were involved in a continuous process of becoming. An FET student teacher came to the following conclusion:

For me, these last two terms were about self-growth and emotional development more than teaching. By emotional development, I do not mean in relation to teaching and my practices but, rather, that it was so much more than just learning how to teach or be a teacher. I learnt what it meant to truly see a learner for who they are and where they come from. I learnt the importance of understanding what makes each individual a person.

The above feelings of personal growth were expressed by several students in both groups as the following student statement indicates: 
Discovering the importance of knowing the learners in this alternative context, and understanding their background and how it at times manifests in the classroom and the learner's behaviour, contributed to my development as a teacher.

Mezirow's (1991) theory of transformative learning argued that through the processes of socialisation and acculturation, people construct meaningful perspectives that can act as perceptual filters through which new perspectives are mediated. The comment below confirms this.

As a white FP student, I was scared to go to my alternative context school. I did not know what to expect from the school nor its community. All I knew about schools in these communities were how young ladies fall pregnant whilst still at school and the drug usage amongst scholars in these schools. Also, how lazy the teachers are at these schools and how they are forever on some form of teacher strike. From my standpoint I thought, "Why can't they do what I am doing? They just need to work hard and concentrate on their schoolwork." My previous mindset forced me to problematise my own upbringing in connection to marginalised communities and structural inequalities. My mentor lecturer and head of programme assisted me as I worked through my anxiety of changing my schooling context.

According to Mezirow (2000) — as well as Freire and Shor (1987)—student teachers, through developing a critical consciousness, learn to contest previously taken for granted "truths," and find authentic meaning amongst the inauthenticities of ruling frameworks that have been held up as unquestionable truths. This is reflected in the following statement by one of the student teachers:

I must say the school and its people received me as I am. I really don't have to pretend to be someone I'm not. I've also learned important stuff . . . about understanding culture, social justice and the world. I used to be ignorant about so many issues affecting children's lives. I just wanted to know how to teach. I was anxious to fill my teaching box with different teaching strategies.

Changing contexts infused student teachers with positivity via their interactions with schools and their mentor teachers. These interactions were facilitated in formal and informal discussions, during classroom discussions, and during break-time conversations.

\section{Step 3: Self-Assessment}

According to Lucas (2012), critical assessment is the ability to look beneath the surface to see what could influence the situation. This capability focuses a student's attention on the root of a problem and transforms previously held perspectives on the matter. Student teachers were encouraged to practice critical self-assessment and to discuss their perceptions, beliefs, and attitudes openly. This step was especially emphasised in active interactions with mentor teachers and engagements with their learners. This is encompassed in the following comment by one of our student teachers: 
The simple understanding of what it means to see the person behind the eyes and show them that they are accepted. It was about laughing together and celebrating with your mentor teacher when the learners start to write their names and tell you the colours. It was about growth both personal and professional.

Student teachers felt that changing SBL contexts made them become very aware of the oppressive experiences that teachers and learners face in schools. They commented on how this impacted on teaching and learning-and especially on their own lives. They also became aware of the power and strengths in these teachers, for example, one of the student teachers stated that:

A teacher is an activist. They don't limit their role to the classroom, but also consider those factors outside the classroom which affect their learners. I realised how poverty limits teachers and learners within the classrooms. Many learners come to school having eaten their last meal at school the previous day. I was encouraged to think differently about the way I teach these learners and to redefine my role as teacher.

Some student teachers became aware that teaching was not only about reaching academic outcomes with learners but that it also involved an understanding of how poverty can impact teaching and learning.

\section{Step 4: Recognition of learning}

During SBL, student teachers can feel very isolated, which would be worse in an unfamiliar schooling context. However, as emphasised in Mezirow's (1991) phases of transformative learning, there often is a strong element of sharing the experience with others in communities. In Step 4, student teachers were encouraged to share their new understandings with others. This was facilitated by having regular reflection sessions for students to share their experience of the alternative context, which assisted in them feeling less anxious and realise that they were not alone in this process. One FET student teacher said:

As I reflect on my own experience of teaching in the alternative context and compare it to what my peers are sharing about their experiences, I realised that I was not alone in this process. That despite my initial fears and anxieties, I learnt from the process. I now see the alternative context in a different light and I am even prepared to consider taking up a teaching position in this context.

Students also reported that it had helped them to bridge the gap between what they learned in their academic modules and how to implement it in practice. This can be seen in the statement below:

Thank you for forcing us to change our SBL schools. As much as I resisted this decision, I recognise the insurmountable value and wisdom of the decision made for us to change to an alternative teaching context. More importantly, I realised that if I stayed in my familiar context I would still be uncritical and unconscious of the 
contextual realities that many learners face within the South African schooling context.

This experience enhanced the critical consciousness of the student teachers. It allowed them to reflect and examine their assumptions, beliefs, and perceptions through a critical lens. This enabled them to question the status quo and to ask critical questions about the inequalities that prevail in the schooling system. It also made them realise that there is something to learn in every context, and that they are able to contribute to social transformation as transformative intellectuals.

\section{Summary of findings}

Four themes were identified during the data analysis: resilience, collaboration and support, personal and professional growth, and recognition and respect for others. Below is an exposition of these themes.

\section{Resilience}

Ungar and Lienbenberg (2011) defined resilience as a positive adaptation that emphasises an individual's personal and social skills, such as professional success. It is evident from data collected and analysed that teaching is not only about the content knowledge, the teaching skills, and the values teachers attach to teaching but also, the importance of understanding the different contextual and societal challenges that impact education. Through their exposure to an alternative SBL context, student teachers started to question the dominant cultures' explanations of the existing social order. Furthermore, the experience allowed them to develop the ability to adjust and adapt to changes brought about by the demands and disappointments that came with exposure to alternative schooling contexts. This stimulated their own creativity, energy, and freedom to seek ideas and offer suggestions on how to improve challenges faced in their classrooms. It also made them more open to learning offered by seasoned teachers who had a good understanding of the context. Student teachers highlighted that they experienced a new sense of purpose, learning about strengths they didn't know they had as well as challenging their weaknesses. Student teachers demonstrated their resilience by confidently communicating their self-belief, openness to learn, and willingness to make a difference. Their resilience was evident in the way they reported on how they dealt with the adversities they faced during SBL. Exposure to alternative SBL contexts, and students subsequently becoming resilient, supports Freire's (1970) call for conscientisation because the experience provided them with an opportunity to learn to perceive social, political, and economic contradictions and to take action against oppressive elements of reality.

\section{Collaboration and support}

Student teachers stressed the mismatch or dissonance between the idealism they entertained about teaching and the lived realities they witnessed teachers, learners, and communities experience. They described this realisation as a painful struggle made easier with others. The 
student teachers provided each other with a reality check in that they were able to confirm many of the same feelings and similar experiences. Student teachers were an important source of support for each other because they provided the solidarity of persons going through the same experiences. Their connectedness with friends, lecturers, and mentor teachers appeared to enhance the student teachers' general wellbeing. Collaboration and support was further enhanced through reflective dialogue. These dialogues were underpinned by Freire's (1970) suggestions that true dialogue occurs under the following conditions: deep love for the world and its people, respect for each other and the world, and a hope for a better future for all. Critical dialogue encourages transformation not only of the individual but of the collective. This was evident in the way student teachers supported each other through the process as well as in the relationships they established with the teachers at schools.

\section{Personal and professional growth}

This research has shown that the listening and the support provided by mentor teachers and their peers were crucial in improving student teachers' capacity to cope with workplace challenges. Student teachers reported that their mentor teachers provided them with a safe space to talk about what they were experiencing. Furthermore, the mentor teachers engaged the student teachers in critically reflecting on the lessons they presented. This mostly served as encouragement and affirmation afforded to the student teachers. Informal comments and suggestions about the way lessons were presented and how these lessons were conceptualised contributed to the professional growth of student teachers. Student teachers also acknowledged the guidance mentor teachers provided by encouraging them to reflect, critique, and interrogate their practices and to take risks. A reciprocal relationship developed where mentor teachers did not position themselves as knowers but availed themselves to listen to student teachers. This encouraged the development of collegial learning spaces. Peters and Pearce (2012) confirmed the above by emphasising the key role that mentor teachers play in establishing collaborative learning cultures for the professional development of mentees. Critical reflection guided student teachers to self-dialogue and inquiry that subsequently led to improved decision-making skills. This fostered self-confidence, creativity, initiative, and self-esteem. Student teachers acknowledged that the experience allowed them to realise that it was not just about achieving their own goals but also about being an agent for social change and contributing to social transformation. There was a consensus that exposure to the alternative SBL contexts was a learning experience that changed students' lives forever.

\section{Recognition and respect for others}

Initially, student teachers felt a sense of discomfort when they were asked about their experiences in the alternative schooling contexts. Contrary to their initial negative assumptions about these contexts, student teachers were surprised and humbled by their own reflection when they conveyed that the change in context was mostly a positive learning experience. They weren't used to having their voices recognised and respected, more importantly, they hadn't recognised and respected the role of their mentor teachers in their understanding of the contextual circumstances impacting on teaching and learning and the 
role schools play in the community. Student teachers also acknowledged that even the challenges that they experienced during SBL became opportunities for learning. Moreover, student teachers reported that schools and communities in some of the alternative contexts managed to confront injustices and to empower and affirm themselves with a self-defined standpoint of "We want education for our children and a better future for all." This helped student teachers recognise and respect the resilience and commitment to education in these dire circumstances as well as recognising the knowledge that the community holds that impacts education. They also expressed their appreciation for the valuable insights gained from shared interest and establishing trust relationships. These relationships were not built around the financial resources schools had but, rather, around the valuable contribution of each of its members. Freire (1970) argued that education often serves to maintain oppressive social orders, but that it can also be used to liberate people and transform society. We believe that requiring student teachers to change SBL contexts served as a catalyst for liberation and social transformation.

\section{Conclusion}

This paper reviewed the body of literature on critical pedagogy and made a case for transformative learning. We attempted to document the qualitative, holistic changes experienced by student teachers as an outcome of the faculty's decision to introduce alternative SBL contexts. The concepts of collaborative inquiry with communities of practice, critical reflection, dialogue, and critiquing assumptions about learning and teaching were highlighted as vital to the development of personal and professional growth. We are of the opinion that these skills will not only enable student teachers to become successful teachers, but also help them to become agents of social change. We believe that the exposure to the unfamiliar SBL contexts helped to address a passive and unquestioning approach to the acquisition of knowledge, and to a teaching methodology out of tune with the context within which genuine teaching and learning needs to takes place. Furthermore, we believe that broadening the schooling context is a promising way to help student teachers build connections and collaborate in ways that examine their assumptions about schooling communities they have not previously been introduced to.

The intention of changing SBL contexts was to develop teachers who can become conscious of their presence in the world. The experience allowed student teachers to critically examine the inequalities that continue to prevail in the South African schoolings system. Student teachers were able to develop a sense of appreciation for the learning opportunities they experienced in the alternative contexts and, in particular, recognised the support and learning offered to them by their mentor teachers. When confronted by the challenges of unfamiliar cultural experiences, attitudes, and values in the alternative school communities, they had the opportunity to develop and strengthen their resilience in order to become transformative intellectuals who can contribute to social transformation. This process also enabled BEd student teachers to deconstruct their notion of what a school is, and to challenge the mental schemas that have informed their notions of what it is to teach and learn and, consequently, how these have influenced the manner in which they expected to be trained as future teachers. 
And, hence, we trust that, where necessary, their previously unquestioned assumptions about themselves and their place in education began to change.

\section{References}

Aliakbari, M., \& Faraji, E. (2011). Basic principles of critical pedagogy. IPEDR, 17, 77-85.

Biesta, G. J. J. (1998). Pedagogy without humanism: Foucault and the subject of education. Interchange, 29(1), 1-16.

Boling, E. C. (2007). Linking technology, learning, and stories: Implications from research on hypermedia video-cases. Teaching and Teacher Education, 23, 189-200.

Botha, L., \& Baxen, J. (2018). Insights from South African students preparing for early childhood teaching: Contexts neglected in teacher preparation. Journal of Education for Teaching, 44(4), 446-460.

Brown, J., \& David, I. (2005). The World Café: Shaping our futures through conversations that matter. Berrett-Koehler.

Brown, J., \& Isaacs, D. (2007). The World Café: Dando forma ao nosso futuro por meio de conversações significativas e estratégicas (1st ed.). Cutrix.

Christie, M., Carey, M., Robertson, A., \& Grainger, P. (2015). Putting transformative learning theory into practice. Australian Journal of Adult Learning, 55(1), 10-30.

Department of Education. (1996). South African Schools Act. Government Printers.

Department of Higher Education and Training (DHET). (2015). Minimum Requirements for Teacher Education Qualifications. Government Printers.

Dirkx, J. M. (1998). Transformative learning theory in the practice of adult education: An overview. PAACE Journal of Lifelong Learning, 7, 1-14.

Favish, J., Ross, D., Inggs, S., Kathard, H., Clarkson, C., Case, J., Collier-Reed, B. I., Reid, S. (2012). Reflections on developing distinctive University of Cape Town graduate attributes. In M. Coetzee, J.-A. Botha, N. Eccles, H. Nienaber \& N. Holtzhausen (Eds.), Developing student graduateness and employability: Issues, provocations, theory and practical guidelines (pp. 207-226). KR.

Fien, J. (1993). Education for sustainable living: An international perspective on environmental education. Southern African Journal of Environmental Education 13, $13-20$.

Fitzpatrick, K. (2013). Critical pedagogy, physical education and urban schooling. Peter Lang. 
Foley, P. C. (2007, October 3-7). A case for and of critical pedagogy: Meeting the challenge of libratory education at Gallaudet University [Paper presentation]. American Communication Association's annual conference. New Mexico.

Freire, P. (1970). Pedagogy of the oppressed. Seabury Press.

Freire, P. (1984). Education in progress path (A. Birshak, Trans.) Kharazmi.

Freire, P. (1996) Pedagogy of the oppressed. Penguin. (Original work published 1972).

Freire, P. (2007). Critical education in the new information. Rowman \& Littlefield.

Freire, P., \& Shor, I. (1987). A pedagogy for liberation: Dialogues on transforming education. Macmillan.

Geduld, D., \& Sathorar, H. (2016). Leading curriculum change: Reflections on how Abakhwezeli stoked the fire. South African Journal of Education, 36(4), 1-13.

Giroux, H. A. (1983). Theory and resistance in education: A pedagogy for the opposition. Bergin \& Garvey.

Giroux, H. A. (1988). Teachers as intellectuals: Toward a critical pedagogy of learning. Bergin.

Habermas, J. (1981). The theory of communicative action. Heinemann.

Keesing-Styles, L. (2003). The relationship between critical pedagogy and assessment in teacher education. Radical Pedagogy, 5(1), 1-20.

Kerr, S. P. (2014). Personal shift: The potential for transformative learning in youth through international service education programs [Unpublished master's thesis]. Royal Roads University, Canada.

Kitchenham, A. (2008). The evolution of John Mezirow's transformative learning theory. Journal of Transformative Education, 6(2), 104-123

Kress, T. M. (2011). Inside the "thick wrapper" of critical pedagogy and research. International Journal of Qualitative Studies in Education, 24(3), 261-266.

Ladson-Billings, G. (2006). From the achievement gap to the education debt: Understanding achievement in US schools. Educational Researcher, 35(7), 3-12.

Lam, C. M., Wong, H., \& Leung, T. T. F. (2007). An unfinished reflexive journey: Social work students' reflection on their placement experiences. British Journal of Social Work, 37, 91-105. 
Lucas, P. (2012). Critical reflection: What do we really mean? Australian Collaborative Education Network National Conference. http://acen.edu.au/2012conference/wpcontent/uploads/2012/11/92_Critical-reflection.pdf

McLaren, P. (1998). Life in school: An introduction to critical pedagogy in the foundation of education. Longman.

McLaren, P. (2003). Life in schools: An introduction to critical pedagogy in the foundations of education. Allyn \& Bacon.

Mezirow, J. (1991). Transformative dimensions of adult learning. Jossey-Bass.

Mezirow, J. (1997). Transformative learning: Theory to practice. Jossey-Bass.

Mezirow, J. (2000). Learning as transformation: Critical perspectives on a theory in progress. Jossey-Bass.

Mountford, M. (2005). The journey toward transformational learning in a statewide doctoral program. Innovative Higher Education, 30(3), 213-237.

Nagda, B. A., Gurin, P., \& Lopez, G. E. (2003) Transformative pedagogy for democracy and social justice. Race Ethnicity \& Education, 6(2), 165-191.

Nouri, A., \& Sajjadi, S. M. (2014). Emancipatory pedagogy in practice: Aims, principles and curriculum orientation. International Journal of Critical Pedagogy, 5(2), 76-87.

Peters, J., \& Pearce, J. (2012). Relationship and early career teachers: A role for school principals. Teachers and Teaching: Theory and Practice, 18(2), 249-262.

Ravitch, S. (2020). Flux pedagogy: Transforming teaching and leading during Coronavirus. Perspectives on Urban Education. https://urbanedjournal.gse.upenn.edu/volume-17spring-2020/flux-pedagogy-transforming-teaching-and-leading-during-coronavirus

Riasati, M., \& Mollaei, F. (2012). Critical pedagogy and language learning. International Journal of Humanities and Social Science, 21(2), 223-229.

Sathorar, H., \& Geduld, D. (2018). Towards decolonising teacher education: Reimagining the relationship between theory and praxis. South African Journal of Education, 38(4), 112. https://doi.org/10.15700/saje.v38n4a1714

Sathorar, H., \& Geduld, D. (2019). Reflecting on lecturer dispositions to decolonise teacher education. Journal of Education, 76, 108-127.

Shor, I. (1992). Empowering education: Critical teaching for social change. University of Chicago Press. 
Shumba, J., Rembe, S., \& Mavuso, M. (2016). Teaching practice purpose and implementation: A concept paper. International Journal of education Science, 13(3), 310-317.

Soudien, C. (2010). Transformation in higher education: A briefing paper. Development Bank of Southern Africa.

Spaull, N. (2019). Equity: A price too high to pay? In N. Spaull \& J. Jansen (Eds.), South African schooling: The enigma of inequality. Springer.

Ungar, M., \& Liebenberg, L. (2011). Assessing resilience across cultures using mixed methods: Construction of the child and youth resilience measure. Journal of Multiple Methods in Research, 5(3), 126-149. 